\title{
Foundational Support Systems of the Smart Grid: State of the Art and Future Trends
}

\author{
Abedalsalam Bani-Ahmed*, Adel Nasiri**, Igor Stamenkovic* \\ *Eaton Corporation, 53051 \\ **Electrical Engineer Department, College of Engineering \& Applied Sciences, University of Wisconsin- \\ Milwaukee, WI 53211 \\ (salamabaniahmed@eaton.com,nasiri@uwm.edu,igorstamenkovic@eaton.com)
}

Received: 15.02.2018 Accepted:10.03.2018

\begin{abstract}
The digitization of the grid is becoming a reality. This transformation has raised various challenges on hardware, controls, communication, and operation. The massive amount of data generated by smart-grid technology can create a practical problem and a reliable infrastructure is required to ensure an uninterrupted operation of smart grid subsystems. Grid modernization is facing a wave of effort to target and to advance every aspect of the smart grid. With the fast paced technology development, the need for intensive resources for smart grid research arises. This paper is intended as a compilation of smart grid research that attracts researchers. State of the art technologies and future trends in smart grid research are discussed within the scope of communications and computing. Challenges of the grid modernization process are tiered and discussed. Sample research efforts have been included for various research paths.
\end{abstract}

Keywords- Communications, Distribution Systems, Industrial IoT, Smart Grid.

\section{Introduction}

The Smart Grid is defined as the digital grid that supports all functional requirements to monitor, control, and optimizes the operation of the electrical grid, improving reliability, efficiency, and modernization [1]. Foundational Support Systems in the Smart Grid (SG) comprises all digital components that support energy industry processes. Information technology (IT) is an example of these processes, with the continuous need to architecture solutions and cyber and physical security measures, and complicated by the critical requirements of Industrial Communications Technologies (ICT) which poses a closer relation to the foundational support systems of smart grid. The Smart Grid faces many noteworthy challenges as the reliability and security features of Smart Grid are in jeopardy. Communication network infrastructure is the key factor and plays the role of a nervous system, which supports monitoring and controlling the grid components. Figure (1) shows the conceptual model of the Smart grid, comprising various domains and interconnected through a foundational support system. 


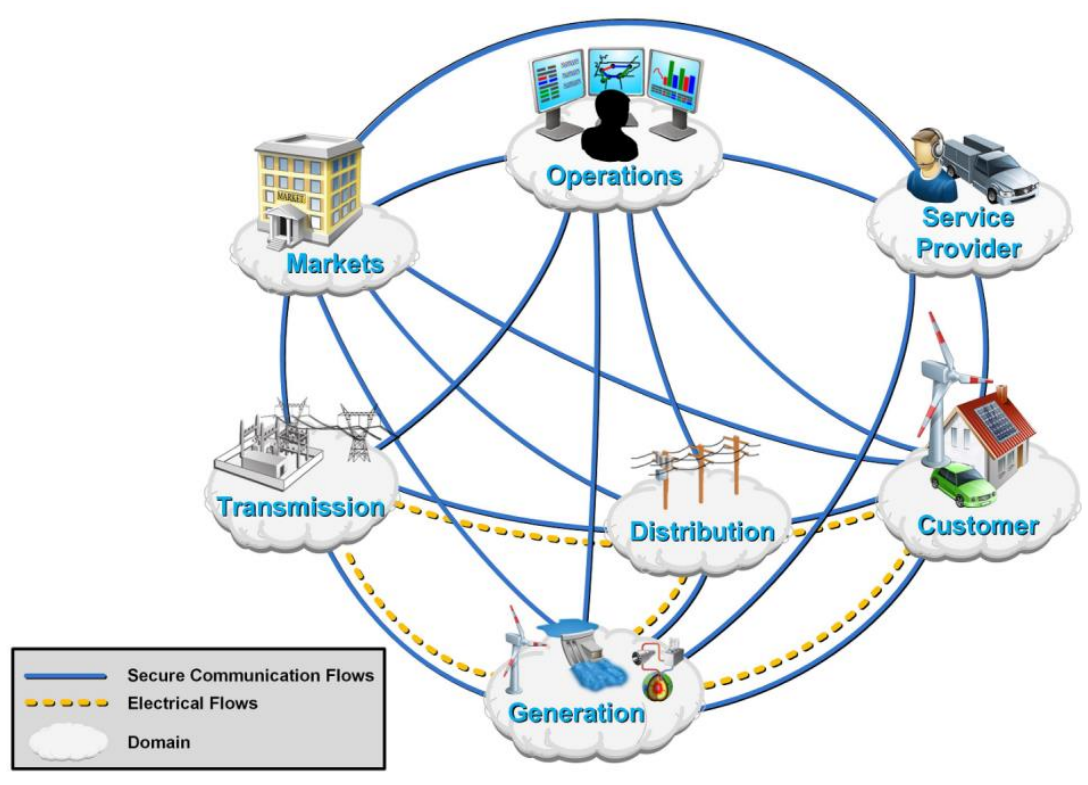

Figure 1. Conceptual Model of the Smart Grid [1].

The Smart Grid vision promises an extensively monitored and operated an interconnected power distribution network that organized generation, transmission, and distribution of electricity by facilitating two-way communications and flow of power other than one way, In comparison with current power grid [4]. In this vision, consumers can provide their excess power to the utility grid in an interactive manner. The grid on the other hand, provides the pricing and usage information over an Advanced Metering Infrastructure [35].

Many drives lie behind the evolution of Smart grids. Mainly, enhancing the capability of producing energy locally (within distribution networks), and consequently reducing energy losses due to distant transmission. Also, the awareness of customers of their individual consumption may help reduce energy consumption and moving them from consumers to producers of power by installing power generation in their resident areas. New challenge arises as the management of non-stationary power generation (e.g. Wind, PV) should be effective and governed efficiently in order not to disrupt the normal operation of the grid.

This paper is intended to serve as a compilation of various Smart Grid research areas, included in communications and computing technologies. It provides a diverse pool of resources provide a global vision of the Smart Grid concept, and render an overlook on the current status of Smart Grid foundation support communication systems.

\section{Current Practices in Smart Grid Interoperability}

The Smart Grid represents an opportunity to modernize the electrical grid by means of reliability, availability, and efficiency. Since the components of the Smart Grid have tremendous variations in nature and uniqueness in purpose, many initiatives have targeted the interoperability and interchangeability of Smart Grid components [4]. There are many initiatives and resources that have been put in place to help support grid modernization and facilitate the transition into a Smart Grid. Many standards and protocols have been implemented and proposed to accommodate the huge number of devices [5]. Some of the standards relate to specific application within a Smart Grid domain. The foundational support system domain has systems into the smart grid environment and enabling them to communicate and exchange information [15].

Smart grid related standards and protocols have been developed by several Standards Development Organizations (SDOs), such as National Institute of Standards and Technology (NIST), and the Institute of Electrical and Electronic Engineers (IEEE) standard committees, International Electro-technical Commission (IEC). A full list of standards can be found in [15].

Table 1 Smart Grid Communications Standards.

\begin{tabular}{|l|l|}
\hline Standard & Description \\
\hline IEC 61970 & $\begin{array}{l}\text { Information model with common objects in the area of electric transmission } \\
\text { ystem. Provides an abstract API for data exchange independent of platform and } \\
\text { echnology. }\end{array}$ \\
\hline IEC 60870-6 & $\begin{array}{l}\text { Control and Data Acquisition (SCADA) over wide area networks (WANs) } \\
\text { IEC 62325 } \\
\text { General guidelines regarding the use of ebXML (ebusiness eXtensible Markup } \\
\text { anguage) technology and architecture for communications in energy markets. }\end{array}$ \\
\hline
\end{tabular}




\begin{tabular}{|c|c|}
\hline Multispeak & $\begin{array}{l}\text { Defines an information model documented in an Extensible Markup Language } \\
\text { XML) schema as well as a communication protocol based on web services and } \\
\text { SOAP). It also provides interoperability among different software applications used } \\
\text { py electric utilities. }\end{array}$ \\
\hline IEEE C37.118 & $\begin{array}{l}\text { Requirements on a phasor measurement unit and relevant communication } \\
\text { protocols for phasor data exchange. The protocol can be based on Ethernet, IP or } \\
\text { ieldbuses. }\end{array}$ \\
\hline IEC 61850 & $\begin{array}{l}\text { Communication networks and systems in substations with the objective to provide } \\
\text { nteroperability between multi-vendor intelligent electronic devices (IEDs), enabling } \\
\text { hem to perform protection, monitoring, control, and automation functions in } \\
\text { substations. }\end{array}$ \\
\hline IEEE C37.1 & IEEE Standard for SCADA and Automation Systems. \\
\hline IEEE 1379 & $\begin{array}{l}\text { Provides implementation guidelines and practices for communications and } \\
\text { nteroperation of IEDs and remote terminal units (RTUs) in an electric substation. }\end{array}$ \\
\hline IEEE 1646 & $\begin{array}{l}\text { Defines communication delays between applications running at end-to-end } \\
\text { pystems, including both processing and transmission delays. }\end{array}$ \\
\hline DNP3 & $\begin{array}{l}\text { DNP stands for Distributed Network Protocol. As an open communication } \\
\text { protocol, DNP3 is generally used in SCADA systems to specify communication } \\
\text { protocols among different components, i.e., a SCADA master station, Remote } \\
\text { Terminal Unites (RTUs) and IEDs. The new version of the DNP3 standard (IEEE } \\
\text { ptd 1815-2012) provides more security features, including the discussion of public } \\
\text { key infrastructure and remote key exchanges. }\end{array}$ \\
\hline Modbus & $\begin{array}{l}\text { Open serial communications protocol, often used in various applications, such as } \\
\text { ndustrial/building automation, energy management, substation automation, etc. } \\
\text { Modbus is used to connect a SCADA master station with RTUs. Modbus defines a } \\
\text { nessaging structure based on master-slave/client-server communications. It } \\
\text { pupports serial (two transmission modes: ASCII and RTU), as well as Ethernet } \\
\text { TCP/IP) protocols }\end{array}$ \\
\hline $\begin{array}{l}\text { OPC Unified } \\
\text { Architecture }\end{array}$ & $\begin{array}{l}\text { A set of standard OLE/COM (Object Linking and Embedding (OLE) for Process } \\
\text { fontrol /Component Object Model) interface protocols that provides } \\
\text { nteroperability between automation and control applications, field systems and } \\
\text { levices, and enterprise applications in the process control industry. The OPC } \\
\text { Jnified Architecture (OPC UA) is developed by the OPC Foundation and } \\
\text { tandardized as IEC 62541. OPC UA defines the communication infrastructure and } \\
\text { nformation model. }\end{array}$ \\
\hline IEEE C37.111 & $\begin{array}{l}\text { Common format for Transient Data Exchange for power systems (COMTRADE) } \\
\text { s a file format, which is used to store electrical parameters (e.g., current, voltage, } \\
\text { power, frequency, etc.) recorded by IEDs during a power systems disturbance event. }\end{array}$ \\
\hline IEEE 1159.3 & $\begin{array}{l}\text { A binary file format designed for exchanging measurement and simulation data } \\
\text { e.g., voltage, current and power measurements) for power quality applications. It } \\
\text { vas initiated by IEEE and EPRI to standardize data formats from a variety of } \\
\text { imulations, measurements and analysis tools for power quality engineers from } \\
\text { many vendors. }\end{array}$ \\
\hline IEEE 61158 & $\begin{array}{l}\text { Fieldbus or IEC } 61158 \text { is an industrial computer network protocol used for real- } \\
\text { ime distributed control. Fieldbus is used at the bottom of the control chain that links } \\
\text { PLCs to field components, for example, sensors, actuators and electric motors. } \\
\text { Fieldbus supports different network structures, e.g., daisy-chain, star, ring }\end{array}$ \\
\hline PROFIBUS & $\begin{array}{l}\text { (Process Field Bus) is a communication protocol for field bus communication, } \\
\text { which is mainly used in the automation technology. There are two types of } \\
\text { ROFIBUS in use today: PROFIBUS DP and PROFIBUS PA, where DP is } \\
\text { pecentralized Peripherals; and PA is Process Automation. The former is used to } \\
\text { pperate sensors and actuators via a centralized controller. The latter is used to } \\
\text { monitor measuring equipment via a process control system }\end{array}$ \\
\hline
\end{tabular}

\section{Architectural Concept}

Network communications have been identified as one of the nine priority areas of research applications and requirements [1]. Other areas include wide area awareness, demand-response, and Distributed Energy Resources (DER), including Energy Storage (ES), Advanced Metering Infrastructure (AMI), Distribution Management Systems (DMS), and cybersecurity. Communications is an integral 
part of all areas, and the method of application with the appropriate infrastructure will broaden the development space of future grid and open the door to innovation.

Figure (2) illustrates the smart grid foundational support systems that led the smart grid to come into fruition. Relative to the smart grid, the Internet of Things (IoT) and (Industrial IoT) are concepts that introduce a massive amounts of data generated by distributed embedded components of a variety of devices, sensors and networked entities, forming a building area network as subsystem of the smart grid. As the data sources at the grid edge, it is practical to utilized the data locally for control and optimization purposes, mitigating unnecessary data transmission to the cloud, and leading to an evolutionary transition to the concept of edge computing. For a building area network, short range communication protocols and standards (wired and wireless) have been adapted by the manufacturers of IoT devices for home and building automation. Table (2) shows examples of these protocols according to the application. Abbreviations the table are described as follows: Dynamic Spectrum Access (DSA) [10], Dedicated short-range communication (DSRC) [11], Wireless Access in Vehicular Environment (WAVE) [12] Worldwide Interoperability for Microwave Access (WiMAX), Long Term Evolution (LTE), - Long Term Evolution Advanced (LTE-A) [13].

Table 2 Examples of Building Area Communication Protocols.

\begin{tabular}{|c|c|c|c|c|}
\hline $\begin{array}{l}\text { Communication } \\
\text { Application }\end{array}$ & Candidates & Protocols used & Frequency & Data rate \\
\hline \multirow[b]{2}{*}{ Short Range } & DSA & IEEE 802.11af & $470-790 \mathrm{MHz}$ & $1 \mathrm{Mbps}$ \\
\hline & DRSC/WAVE & IEEE $802.11 p$ & $5.850-5.925 \mathrm{GHz}$ & 3-27 Mbps \\
\hline \multirow{3}{*}{ Wide Range } & Wi-Fi & IEEE $802.11 \mathrm{a} / \mathrm{b} / \mathrm{g}$ & $2.4-5 \mathrm{GHz}$ & 1-54 Mbps \\
\hline & WiMAX & IEEE 802.16 [24] & $1.25-20 \mathrm{MHz}$ & $\begin{array}{l}30 \text { Mbps - } 1 \\
\text { Jbps }\end{array}$ \\
\hline & LTE/LTE-A & & $\begin{array}{l}20 \mathrm{MHz}-100 \\
\mathrm{MHz}\end{array}$ & $\begin{array}{l}300 \text { Mbps }-3 \\
\text { Sbps }\end{array}$ \\
\hline
\end{tabular}

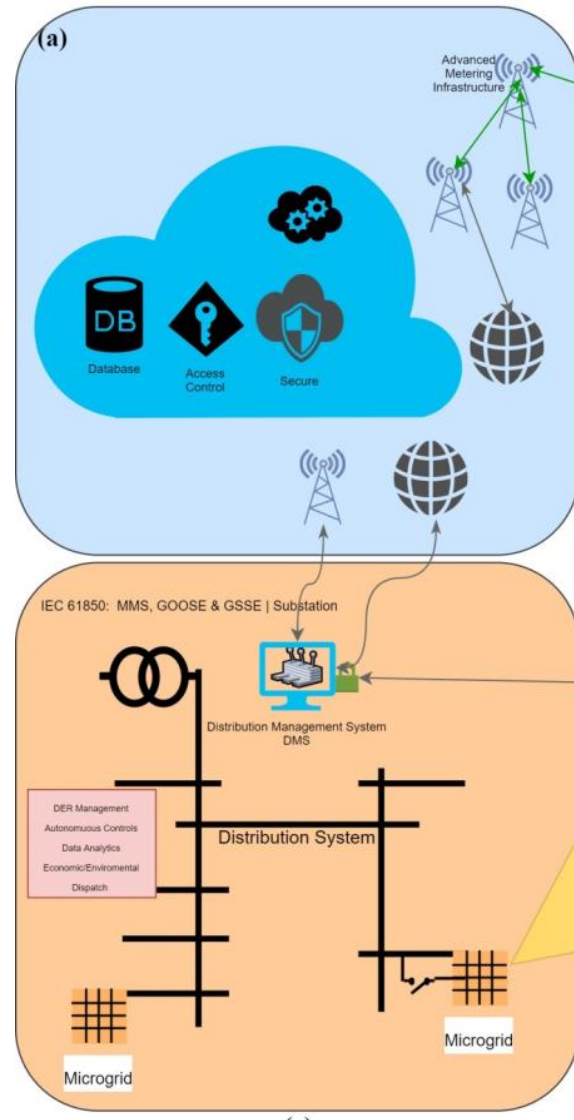

(c)

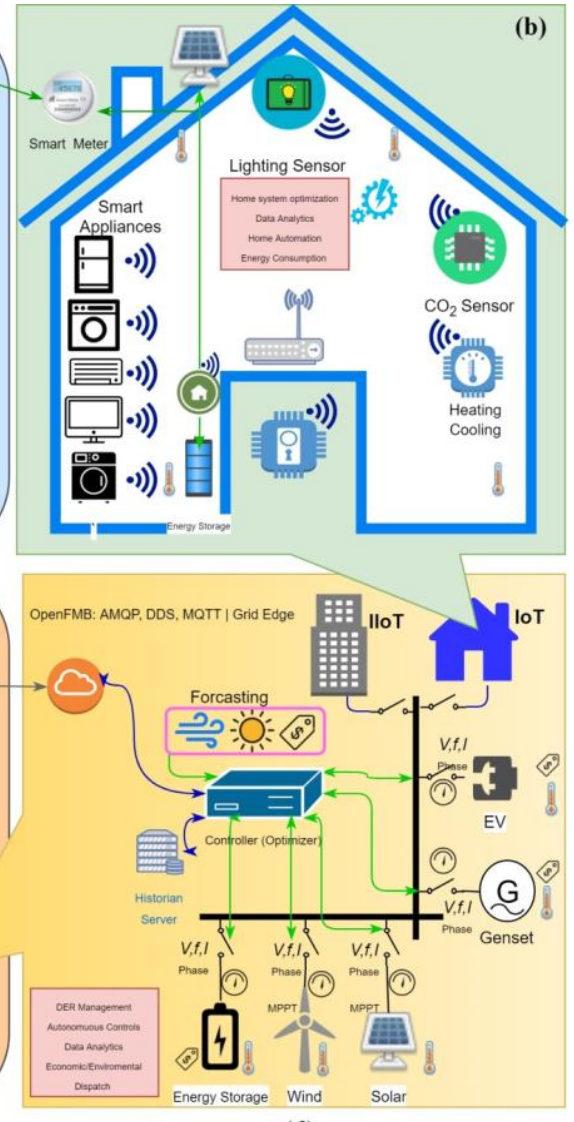

(d)

Figure 2. Layered diagram of Smart Grid. 
At the grid level, the main focus of smart grid related efforts is the integration of DERs into the current grid. Power electronics technologies have advances that added potential functions that are not available in traditional power plants, such as plug-and-play [24] capability for AC and DC buses. At the cyber level, new power electronics technology also support an open-standard-based communication interfaces so that any device connected can be recognized by the grid as soon as it is plugged in. The open-standard communication protocol must be able to describe smart loads, various storage devices, and generation devices. The DERs are integrated into the grid as Distributed Energy Resources Management Systems (DERMS), the involves the system controller [38], communication protocols [37], intelligent systems (i.e. using forecasted data to improve efficiency), as illustrated in Figure (2-(d)).

\section{Current State of Research in Smart Grid Communications}

i. Overview

The next generation grid has a centralized and a distributed nature. Unlike the current grid, the centric generation is not the only generation source across the grid system, and the implementation is optimized stochastically based on economic and environmental goals. The Smart grid is all about coupling subsystems electronically while maintaining localized controls, flexibility, and efficiency.

Figure 2.a illustrates the concepts of cloud/edge computing in the smart grid. The main benefit from edge computing is to avoid higher response time and power consumption in comparison to a cloud computing solution. The smart grid benefits of both cloud and edge computing depending on the application and the necessity of the cloud involvement. The rest of this section provides some examples of the current implementations.

ii. Distributed Energy Resources Management Systems

Distributed Energy Resources Management Systems (DERMS) is an operational technology system. The system receives a consistent and often frequent flow of data from the field. The data could come through the head end of an existing Supervisory Control and Data Acquisition (SCADA) system, wide-area network or field-area network, or it could come through a public network [38].

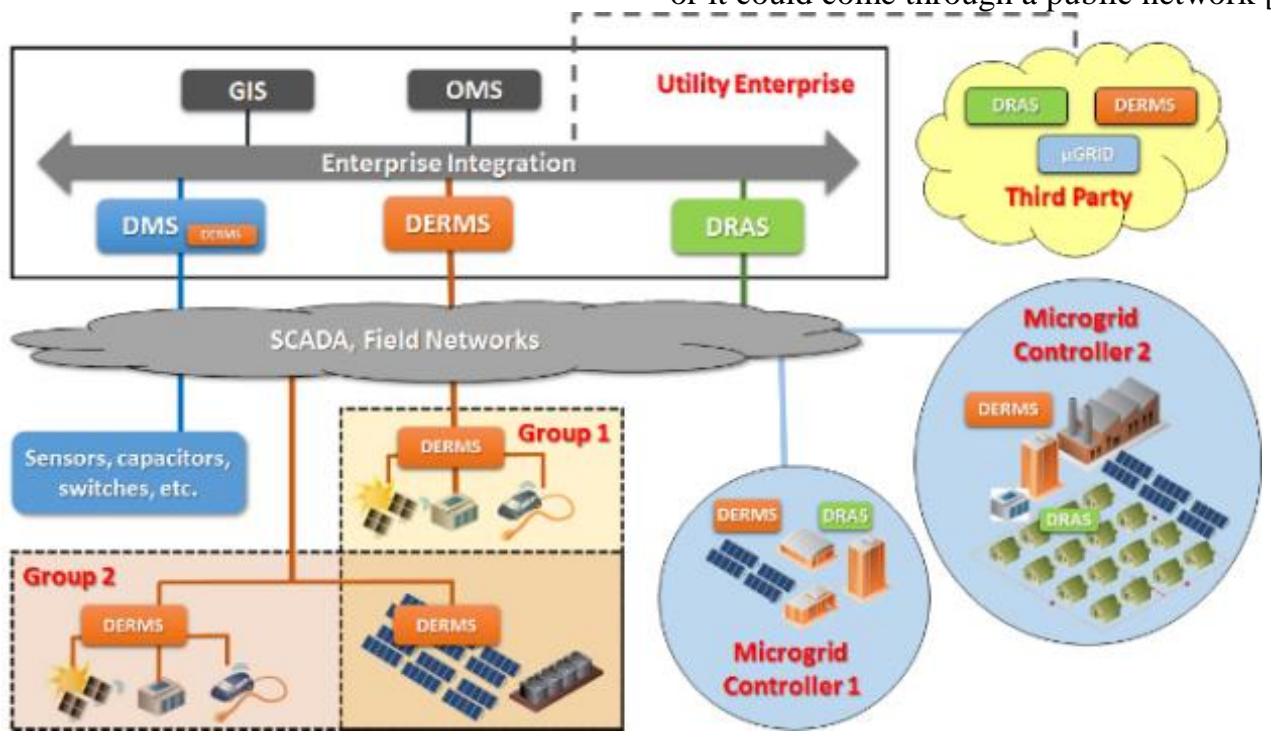

Figure 3. An architectural view of distributed energy resources management system [38].

A DERMS is constantly processing and optimizing the use of a portfolio of distributed energy resources over which the system has control. The optimization could take a variety of forms, which depend on the use cases, contract structures and value streams at the wholesale, distribution and customer-premise levels. To perform optimization of DERs, the DERMS must incorporate short-term forecasts for generation, consumption and storage of energy in order to determine the optimal course of action in the coming seconds, minutes, hours and days. Following the completion of each optimization calculation, a DERMS will provide suggested actions to operators, traditional field assets, thirdparty DER owners or DERs themselves via an human- machine interface (HMI) or communication channel. For DERs and third-party owners, the communication channel can take the form of price signals, offers or direct control.

\section{iii. Microgrids}

Microgrids can be defined as a set of interconnected distributed energy resources (DER) and loads (critical and non-critical) at low-voltage that acts as a single controllable entity in order to operate in two modes (gird-connected or island) with respect to the utility grid [24]. Figure 4 shows the components of a microgrid control system. 


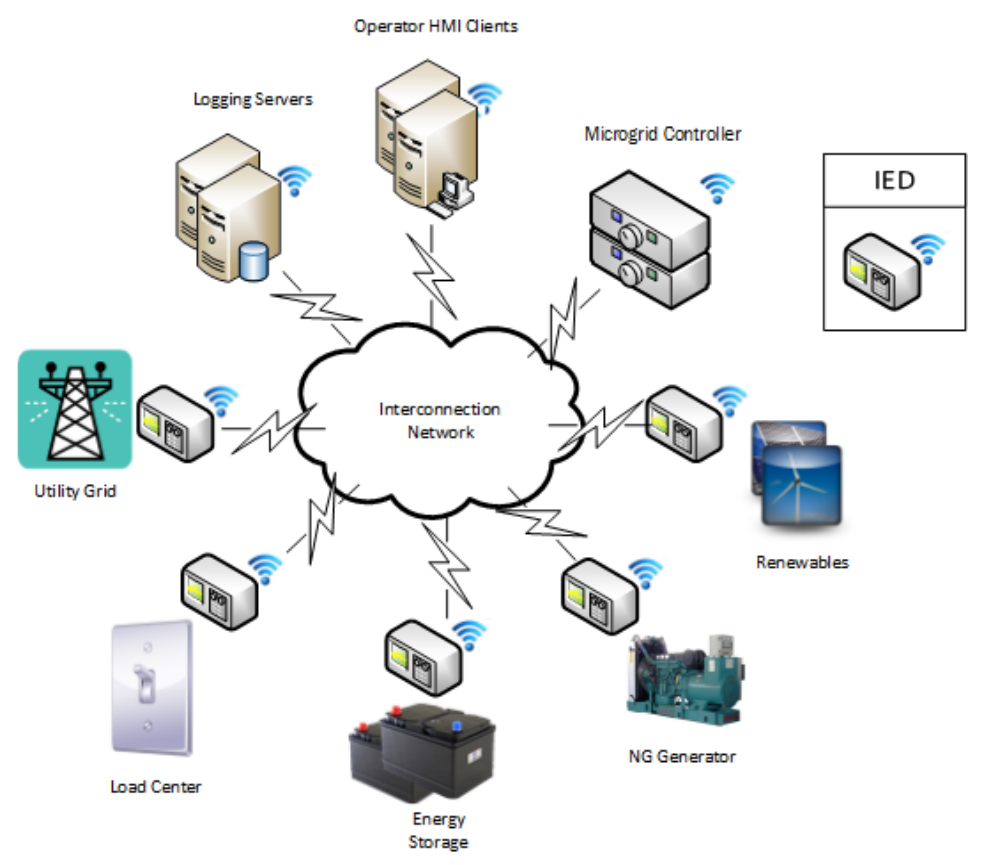

Figure 4. Structure of microgrid components and communications.

Generic power system architecture consists of three major layers. As shown in Figure 5, the first layer (bottom) is the power equipment layer, which contains the distributed energy sources, relays and breakers. The second layer is the communication layer, which contains the cyber-physical network backbone and the communication protocols and standards. The third layer is the control layer.

Data traffic starts from the power system layer, where the components update their status data and measurements through the communication layer. Status data can be breaker status, device warnings and flags, measurements of voltage, active and reactive power, and frequency of each power component. The control layer receives data from the communication layer, validates the received information and synchronizes clocks. Ensuring that the data received is the most recent measurements, considering possible delays or dropped data packets within the communication layer. Unit commitment and control algorithm process the inputs and sends back commands through the communication layer, which is responsible of routing the commands to the designated power component.

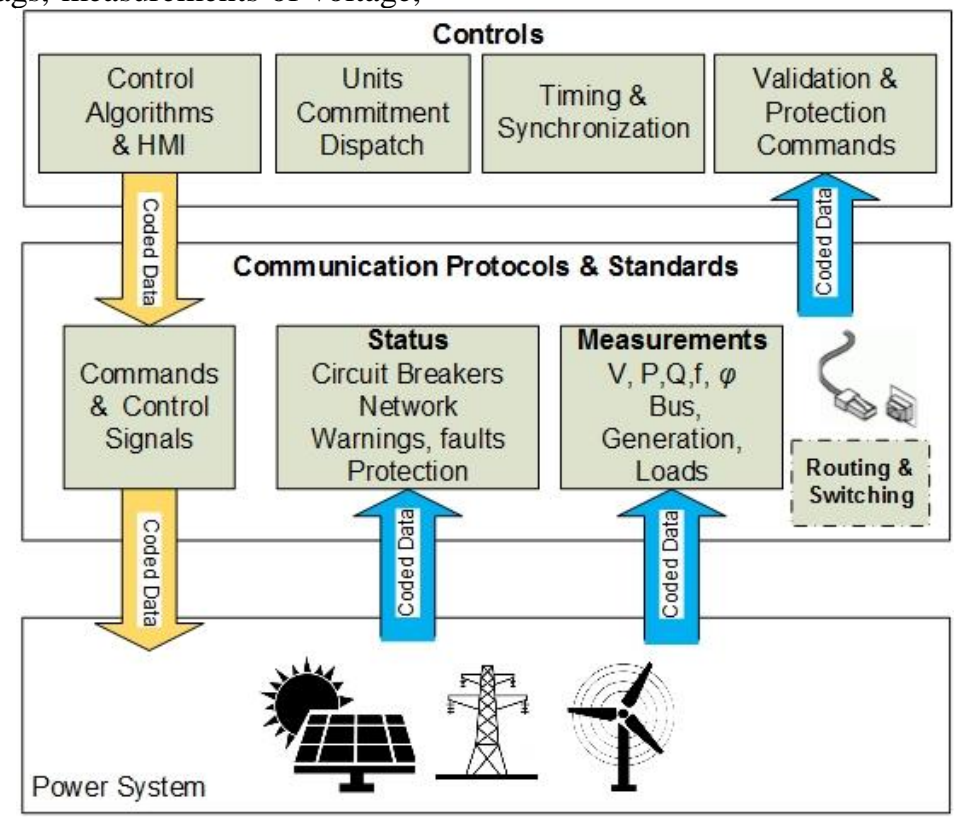

Figure 5. A diagram of generic power control system. 
Power system controls employ several protocols to enable reliable communications between the power system layer and control layer. The most widely used communication protocol is the Internet protocol suite (TCP/IP). The amount of development and architecture dedicated to the suite, and its non-proprietary nature has empowered this protocol to be dominant. As a part of this layered protocol suite, the application layer consists of protocols that govern processto-process communication, enabling data sharing within the host or between different hosts. Examples of protocols used between components in process automation systems are, Modbus, Control Access Network (CANbus), and Distributed Network Protocol (DNP3), which is the dominant protocol in SCADA networks for substation automation. More detailed list of protocols are provided in the previous section.

In power system architecture, the controller may communicate with the power components the standard IEC 61850 over Ethernet using TCP/IP. Network backbone ensures reliable and secure communication between components by employing an Internet communication protocol suite, which also may contain routing and switching. The architecture also suggests the presence of Human Machine Interface (HMI) clients for monitoring and controlling purposes, a data logging server that records system data at regular intervals, and an event recorder that captures predefined events with high time resolution. Communication layer handles data from the power components and transmission to the controller as feedback to the control layer [36].

\section{iv. Distribution Management Systems}

The Distribution Management Systems (DMS) is a pool of applications that monitor and control a distribution network. DMS is an integral part of the Smart Grid that sits firmly in the middle of Smart Grid transition requirements, and provides the basis from which to model operation and direct field activities in a safe and efficient manner. It also serves as an operations platform, automating tasks and filtering information for the operator. For a utility, it is the strategic system that will enable management of a Smart Grid and will leverage its benefits. has a control room focus in assisting the operator to maintain and operate the system in secure state, minimizing losses and optimizing the lines power flow capacity. DMS coordinates real-time functions within the distribution network with the non-real-time (manually operated devices) information needed to properly control and manage the network on a regular basis. The key to a DMS is the organization of the distribution network model database, access to all supporting industrial control technology (ICT) infrastructure and applications necessary to populate the model and support the other daily operating tasks. DMS functionality can be divided into three categories: 1) System monitoring 2) Decision support 3) Control actions [16].

Implementing a DMS solution requires the integration of many different elements - field equipment, communications, control centers and supporting systems within the utility enterprise. This establishes a total solution for the utility to achieve its business objectives in the reliable delivery of power to its consumers. To achieve this goal, many industrial alliances were started [15]. Open Field Message Bus (OpenFMB) represents one of the results of these effort to overcome the wide area of communications and by utilizing the existing standards to define a framework and reference architecture enabling grid edge interoperability and enhances integration among multi-vendor field devices.

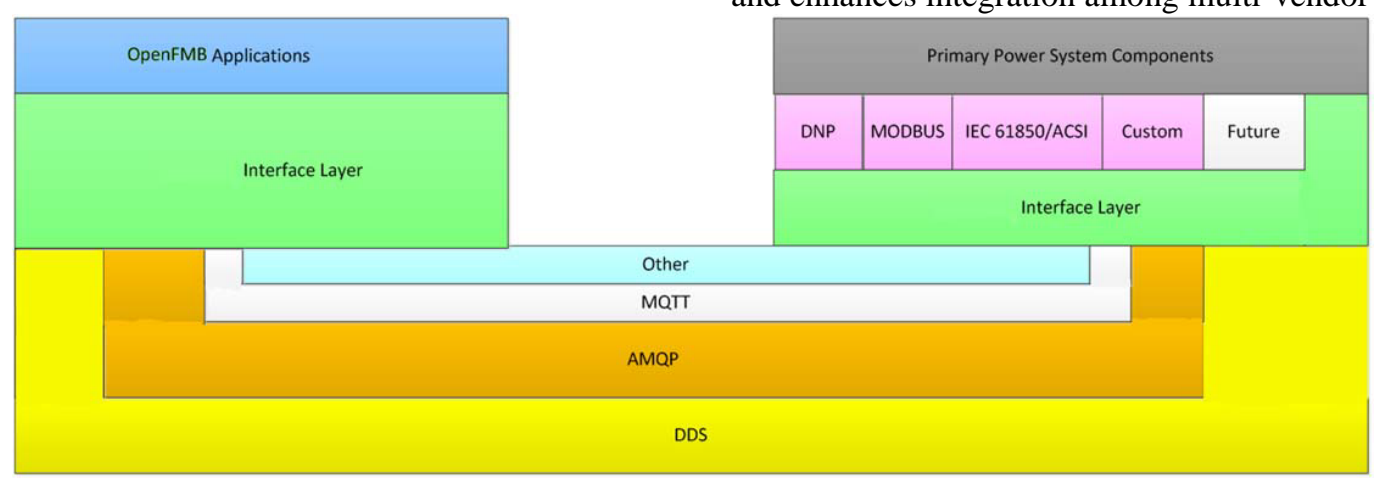

Figure 6. Overview of OpenFMB node architecture [openFMb website]

Figure 6 shows the general concept of the OpenFMB node architecture. The application part provides the necessary grid services that relate to the designated component. OpenFMB Adapters interface the field message bus with power system components utilizing protocols, such as DNP3, Modbus, or IEC 61850, as described in DERMS communications. The wider range of communications adapts different Publish-Subscribe protocols, such as Advanced Message Queuing Protocol (AMQP) [17], Data Distribution Systems (DDS) [18] [19], or message Queuing Telemetry Transport (MQTT) [20], utilized for communications between Open FMB nodes. A list of IoT Publish-Subscribe protocols are in Table (3). The protocols are categorized into three classes: Device to Device (D2D) protocols for independent communication of smart devices, Device to Server (D2S) protocols for transport of collected data from devices to server infrastructure and vice versa, and Server to Server (S2S) protocols for intercommunication of applications on servers 
Table 3 Sample IoT Publish-Subscribe protocols

\begin{tabular}{|c|c|c|}
\hline Protocol & Class & Remark \\
\hline MQTT: Message Queue Telemetry Transport & D2S & Broker Based \\
\hline DDS; Data Distribution Service & D2D & Data bus based \\
\hline XMPP: Extensible Messaging and Presence Protocol & D2S & Messaging \\
\hline AMPQ: Advanced Message Queueing Protocol & D2S & Message With Queuing \\
\hline SOAP: Service Oriented Architecture Protocol & S2S & Web Services \\
\hline
\end{tabular}

Figure 7 illustrate the main difference between D2D class protocol and D2S protocol. Protocols such as MQTT and AMQT (Fig. 6-a) use a broker where all communication routes are managed by a broker [20]. Devices in this protocol subscribe on certain data models according to the application design. Devices and applications such as DDS

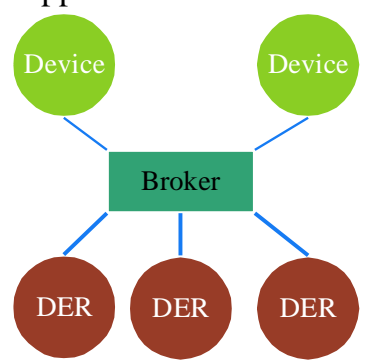

(a) communicate through a data-centric messaging bus. Some smart grid applications that relate to distribution management systems may leverage a combination between the two types in order to maintain continuous data traffic between field devices as well as an up-to-date awareness of the grid status from the DMS perspective.

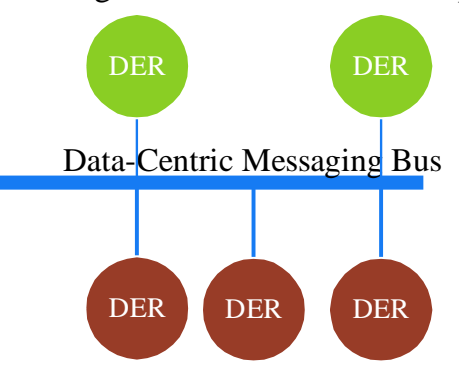

(b)

Figure 7. (a) Publish-Subscribe protocol using a broker (b) Publish-Subscribe protocol using a message bus.

\section{Future trends in Smart Grid research}

The realm of Smart Grid involves two main paths of research, the development of new technology improving the available state of the art equipment, and providing connectivity solutions for integrating legacy equipment. These two categories fall mainly into two visions of the Smart Grid, as they relate to the digital layer of the Smart Grid: The computing and communications visions. The following provides a categorized review of current research that contributes to communications and computing developments on Smart Grid.

Figure 8 shows the domain contributions of computing and communications to the smart grid development. Computing and communications involve the enabling technologies that contribute to the functional and architectural concepts of smart grid.

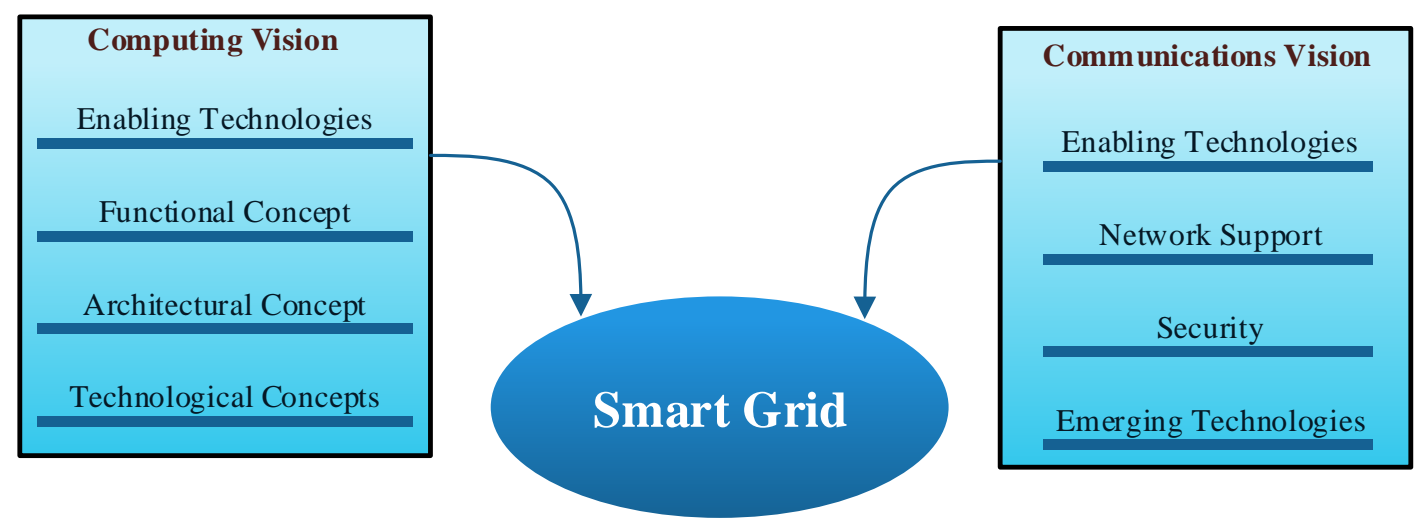

Figure 8. Smart grid vision from the perspective of computing and communications. 


\section{i. $\quad$ Computing}

Three-tiered approach is adopted in order to categorize the focus areas by projecting thee concepts: Architectural concept, functional concept, and technological concept. The architectural concept provides comprehensive architectural areas that provide context for the functional concept. Functional concepts describing desired outcomes to specific Smart Grid goals by categorizing clusters of functional area. The concept research areas contribute to multiple architectural concepts. The functional concept provides a

\begin{tabular}{|c|c|c|}
\hline Tier & Concepts & Research Area \\
\hline \multirow[t]{3}{*}{$\begin{array}{l}1 . \\
\text { concept }\end{array}$} & $\begin{array}{l}\text { Supply-side } \\
\text { [24] }\end{array}$ & $\begin{array}{l}\text { Higher penetration of renewable resources [24] } \\
\text { Energy Storage and balancing } \\
\text { Integrated zones of renewable energy grid } \\
\text { Smart grid of isolated islands }\end{array}$ \\
\hline & Demand-side [30] & $\begin{array}{l}\text { Utility control } \\
\text { Aggregated local energy } \\
\text { Self-owned base energy } \\
\text { Electric transportation }\end{array}$ \\
\hline & Smart Grid System & $\begin{array}{l}\text { System architecture (coherent system operations) } \\
\text { System Performance } \\
\text { System security }\end{array}$ \\
\hline \multirow[t]{3}{*}{$\begin{array}{ll}2 . & \text { Functional } \\
\text { Concept } & \end{array}$} & Systemic functions & $\begin{array}{l}\text { Information, control security. } \\
\text { Privacy, instruction tolerance. } \\
\text { Automation. }\end{array}$ \\
\hline & Enabling functions [34] & $\begin{array}{l}\text { State awareness. } \\
\text { Failures and emergency response. } \\
\text { Markets: policy operations and design. }\end{array}$ \\
\hline & Performance functions & $\begin{array}{l}\text { Operations: bulk system transmission, congestion } \\
\text { detection and power flow forecasting. } \\
\text { Island-to-island power flow control and } \\
\text { coordination. }\end{array}$ \\
\hline \multirow[t]{4}{*}{$\begin{array}{l}3 . \quad \text { Technologic } \\
\text { al Concepts }\end{array}$} & $\begin{array}{l}\text { Distributed systems } \\
\text { architecture } \\
{[24]}\end{array}$ & $\begin{array}{l}\text { Self-integrating systems. } \\
\text { Multi-agent architecture. } \\
\text { Virtual computing. } \\
\text { Message-oriented middleware. }\end{array}$ \\
\hline & Computer Applications & $\begin{array}{l}\text { Market inspired controls. } \\
\text { Monitoring and control modeling. } \\
\text { Protection. } \\
\text { State estimation. } \\
\text { Corrective control analysis. } \\
\text { Asset management. }\end{array}$ \\
\hline & Information Science & $\begin{array}{l}\text { Visualization. } \\
\text { Artificial Intelligence. } \\
\text { Real-time systems. } \\
\text { Software verification and validation. }\end{array}$ \\
\hline & Cyber security [32] [33] & Refer to Communications Vision \\
\hline
\end{tabular}

Computing related areas are mostly located within the technological concepts. Given the distributed nature of smart grids, coordination of multi-agent systems (MAS) [24] regardless the nature of the agent is essential. For example, if we consider the smart grid domains described before, we can see the necessity of algorithms that governs the coordination between all agents (DERMS, Microgrids, etc.). Generally, massive amount of data collected from the field must be processed fast enough to maintain an up-to-date state of the whole system. However, artificial intelligence algorithms can be time consuming, and development of linking role in term of areas of applications for the technological concept areas. [6].
Higher penetration of renewable resources [24]

Energy Storage and balancing

Integrated zones of renewable energy grid

Utility control

Aggregated local energy

Self-owned base energy

System Performance

System security

Operations: bulk system transmission, congestion

ection and power flow forecasting. coordination.

Self-integrating systems

Multi-agent architecture.

Market inspired controls.

Monitoring and control modeling.

ection.

Asset management.

Real-time systems.

Software verification and validation. machine learning capabilities can be challenging but very rewarding in the number of smart grid applications that can be developed, such as corrective controls, fault-tolerant systems, market inspired configurations, and state estimation [34].

\section{ii. $\quad$ Communications}

The computing vision overlaps with vision with communications related areas. The wider vision of smart grid can be categorized into three main tiers: Universal Connectivity, Resilience and recovery, and cyber security. 
INTERNATIONAL JOURNAL of SMART GRID, ijSmartGrid

Abedalsalam B. A. et al. ,Vol. 2, No. 1, March, 2018

Privacy and security policies can be considered as categories in addition to home area communications.

\begin{tabular}{|c|c|c|}
\hline Tier & Concepts & Research Area \\
\hline \multirow{3}{*}{$\begin{array}{l}\text { 1. Enabling } \\
\text { echnologies }\end{array}$} & Architecture [23] & Nanoscale communications \\
\hline & Power line communications [27] & $\begin{array}{l}\text { Development and adjustment of PLC } \\
\text { solutions }\end{array}$ \\
\hline & Power line-borne optical fiber [25] & $\begin{array}{l}\text { Power line-borne optical fiber Impact } \\
\text { of superconductor power lines } \\
\text { Power line without wire }\end{array}$ \\
\hline \multirow{2}{*}{$\begin{array}{l}\text { 2. Network } \\
\text { Support }\end{array}$} & Networking Technologies [23] [25] & Scalability and Interoperability. \\
\hline & $\begin{array}{l}\text { Quality of Service (QoS) Mechanisms } \\
\text { and Traffic Characteristics.[29] }\end{array}$ & $\begin{array}{l}\text { QoS algorithms for multiple } \\
\text { nterconnected applications } \\
\text { Latency Impacts and Modeling }\end{array}$ \\
\hline \multirow[t]{2}{*}{ 3. Security } & Security [32] [33] & $\begin{array}{l}\text { IPv6 } \\
\text { Risk analysis }\end{array}$ \\
\hline & Security Standards & $\begin{array}{l}\text { International security standards and } \\
\text { egislation for SCADA security. }\end{array}$ \\
\hline \multirow{2}{*}{$\begin{array}{l}\text { 4. Emerging } \\
\text { Technologies }\end{array}$} & Solid State Transformers [31] & Plug-and-play interfacing. \\
\hline & Quantum Key Distribution [35] & Secure communication for AMI \\
\hline
\end{tabular}

\section{Conclusions}

The Smart Grid The smart grid incorporates advanced networking technology, including sensors and controls that make it possible to monitor electricity use in real time and make automated control to optimize the operation economically and environmentally. The massive amount of data transmitted over the network requires high availability of the system. This paper introduced the current practices in Smart grid foundational support systems, involving computing and communication infrastructure. The architectural concept of the foundational support is described according to the level of the subsystem in the Smart Grid hierarchy, i.e. Microgrid, DERMS, DMS. A future vision in Smart Grid research is categorized into computing and communications. The bottleneck in the practical side of Smart Grid implementation is concentrated in the cyber-security aspect. Security standards and protocols are being introduced as a solution the cybersecurity issue. The goal however is still unclear, as the subsystems of the Smart Grid has boundless number of variations in architecture, purpose, controls, and critical data.

\section{References}

[1] NIST Framework and Roadmap for Smart Grid Interoperability Standards, Release 1.0. 2010 [Available online www.nist.gov].

[2] R. E. Pérez-Guzmán, Y. Salgueiro-Sicilia and M. Rivera, "Communications in smart grids," 2017 Conference on Electrical, Electronics Engineering, Information and Communication Technologies (CHILECON), Pucon, Chile, 2017, pp. 1-7.
[3] M. M. Fouda, Z. M. Fadlullah, N. Kato, R. Lu and X. S. Shen, "A Lightweight Message Authentication Scheme for Smart Grid Communications," in IEEE Transactions on Smart Grid, vol. 2, no. 4, pp. 675685, Dec. 2011.

[4] M. Kuzlu, M. Pipattanasompom and S. Rahman, "A comprehensive review of smart grid related standards and protocols," 2017 5th International Istanbul Smart Grid and Cities Congress and Fair (ICSG), Istanbul, 2017, pp. 12-16.

[5] M. G. Kanabar, I. Voloh and D. McGinn, "A review of smart grid standards for protection, control, and monitoring applications," 2012 65th Annual Conference for Protective Relay Engineers, College Station, TX, 2012, pp. 281-289.

[6] "IEEE Smart Grid R\&D Committee: Process and Synopsis of Collation of Topics" IEEE Smart Grid R\&D committee. 2018 [Available online: smartgrid.ieee.org]

[7] E. Kabalcı, E. Irmak, I. Çolak, "Design of an AC-DCAC converter for wind turbines", International Journal of Energy Research, Wiley Interscience, DOI: 10.1002/er.1770, Vol. 36, No. 2, pp. 169-175. (Article)

[8] I. Çolak, E. Kabalci, R. Bayindir R., and S. Sagiroglu, "The design and analysis of a 5-level cascaded voltage source inverter with low THD", 2nd PowerEng Conference, Lisbon, pp. 575-580, 18-20 March 2009. (Conference Paper) 
[9] IEEE Standard 519-1992, Recommended practices and requirements for harmonic control in electrical power systems, The Institute of Electrical and Electronics Engineers, 1993.

[10]A. B. Flores, R. E. Guerra, E. W. Knightly, P. Ecclesine and S. Pandey, "IEEE 802.11af: A Standard for TV White Space Spectrum Sharing," IEEE Communications Magazine, vol. 51, no. 10, pp. 92100, 2013.

[11] IEEE Std 802.11p, "IEEE Standard for Information Technology Part 11: Wireless LAN Medium Access Control (MAC) and Physical Layer (PHY) specifications Amendment 6: Wireless Access in Vehicular Environments," 2010.

[12] IEEE 802.11: Wireless LANs.

[13] IEEE 802.16: Broadband Wireless Metropolitan Area Networks (MANs).

[14] US Department of Energy, "2014: Smart Grid System Report, A Report to Congress", 2014.

[15] https://sepapower.org / (last accessed on 02/02/2017)

[16] M. Rezkalla, K. Heussen, M. Marinelli, Junjie Hu and H. W. Bindner, "Identification of requirements for distribution management systems in the smart grid context," 2015 50th International Universities Power Engineering Conference (UPEC), Stoke on Trent, 2015, pp. 1-6.

[17] https://www.amqp.org/ (Accessed 02/01/2018)

[18] http://portals.omg.org/dds/ (Accessed 02/01/2018)

[19] M. Cintuglu, T. Youssef and O. Mohammed, "Development and application of a real-time testbed for multiagent system interoperability: A case study on hierarchical microgrid control," 2017 IEEE Power \& Energy Society General Meeting, Chicago, IL, USA, 2017

[20] Mqtt.org. (Accessed 02/01/2018)

[21]P. Peniak and M. Franekova, "Open communication protocols for integration of embedded systems within Industry 4," 2015 International Conference on Applied Electronics (AE), Pilsen, 2015, pp. 181-184.

[22] Pimmy Gandotra, Rakesh Kumar Jha, "Device-toDevice Communication in Cellular Networks: A Survey", Journal of Network and Computer Applications, Volume 71, 2016, Pages 99-117.

[23] M. S. Islam and V.J. Logeeswaran, "Nanoscale Materials and Devices for Future Communication Networks," IEEE Communications Magazine, vol. 48, no. 6, pp. 112-120, June 2010.
[24] A. Bani-Ahmed, A. Nasiri and H. Hosseini, "Design and development of a true decentralized control architecture for microgrid," 2016 IEEE Energy Conversion Congress and Exposition (ECCE), Milwaukee, WI, 2016, pp. 1-5.

[25]IEEE Standard for Interconnecting Distributed Resources with Electric Power System, IEEE Std. 1547TM-2003, July 2003.

[26] J. M. Guerrero, M. Chandorkar, T. L. Lee and P. C. Loh, "Advanced Control Architectures for Intelligent Microgrids-Part I: Decentralized and Hierarchical Control," in IEEE Transactions on Industrial Electronics, vol. 60, no. 4, pp. 1254-1262, April 2013.

[27] S. Galli, A. Scaglione and Z. Wang, "Power Line Communications and the Smart Grid," 2010 First IEEE International Conference on Smart Grid Communications, Gaithersburg, MD, 2010, pp. 303308.

[28]R. A. Spalding et al., "Fault Location, Isolation and service restoration (FLISR) functionalities tests in a Smart Grids laboratory for evaluation of the quality of service," 2016 17th International Conference on Harmonics and Quality of Power (ICHQP), Belo Horizonte, 2016, pp. 879-884.

[29] K. Basu, A. Maqousi, T. Balikhina and F. Ball, "Network level Quality of Service (QoS) challenges for smart grid measurement and control systems," 2017 2nd International Conference on the Applications of Information Technology in Developing Renewable Energy Processes \& Systems (IT-DREPS), Amman, Jordan, 2017, pp. 1-5.

[30] K. Wang, H. Li, S. Maharjan, Y. Zhang and S. Guo, "Green Energy Scheduling for Demand Side Management in the Smart Grid," in IEEE Transactions on Green Communications and Networking, vol. PP, no. 99, pp. 1-1.

[31]M. Rashidi, A. Bani-Ahmed and A. Nasiri, "Application of a multi-port solid state transformer for volt-VAR control in distribution systems," 2017 IEEE Power \& Energy Society General Meeting, Chicago, IL, USA, 2017, pp. 1-4.

[32] Y. Wang et al., "Analysis of Smart Grid security standards," 2011 IEEE International Conference on Computer Science and Automation Engineering, Shanghai, 2011, pp. 697-701.

[33]F. Ye and Y. Qian, "A Security Architecture for Networked Internet of Things Devices," GLOBECOM 2017 - 2017 IEEE Global Communications Conference, Singapore, 2017, pp. 16. 
[34]A. Bani-Ahmed, M. Rashidi and A. Nasiri, "Coordinated failure response and recovery in a decentralized microgrid architecture," 2017 IEEE Energy Conversion Congress and Exposition (ECCE), Cincinnati, OH, 2017, pp. 4821-4825.

[35] R. Ullah, Y. Faheem and B. S. Kim, "Energy and Congestion-Aware Routing Metric for Smart Grid AMI Networks in Smart City," in IEEE Access, vol. 5, pp. 13799-13810, 2017.

[36]Zhu Yongli; Wang Dewen; Wang Yan; Zhao Wenqing, "Study on interoperable exchange of IEC 61850 data model," Industrial Electronics and Applications, 2009. ICIEA 2009. 4th IEEE Conference on , vol., no., pp.2724,2728, 25-27 May 2009.

[37] A. Bani-Ahmed, L. Weber, A. Nasiri and H. Hosseini, "Microgrid communications: State of the art and future trends," 2014 International Conference on Renewable Energy Research and Application (ICRERA), Milwaukee, WI, 2014, pp. 780-785.

[38] Grid Interactive Microgrid Controllers and the Management of Aggregated Distributed Energy Resources (DER): Relationship of Microgrid Controller with Distributed Energy Resource Management System (DERMS) and Utility Distributed Management System (DMS). EPRI, Palo Alto, CA: 2015. 3002007067.

[39]D. Kumar, H. Singh and Reshma, "A review on industry challenges in smart grid implementation," 2016 7th India International Conference on Power Electronics (IICPE), Patiala, 2016, pp. 1-5. 